\title{
JUEGOS Y JUGUETES LIBRES. LA FILOSOFÍA Y OBSESIÓN DE WALTER BENJAMIN
}

\author{
Free Games and Toys. The Philosophy and Obsession of Walter Benjamin
}

\author{
Jordi Brasó Rius ${ }^{1}$ \\ jbraso@asesport.cat \\ Universitat de Barcelona. España \\ Jordi Garcia Farrero² \\ jgarciaf@ub.edu \\ Universitat de Barcelona. España \\ Fecha de recepción: 30/03/2020 \\ Fecha de aceptación: 16/05/2020
}

Resumen: Los juegos y los juguetes tienen que tratarse desde diferentes puntos de vista si queremos hacernos una idea global de su importancia. Por todo ello, es necesario analizar diferentes personajes que han tratado las diferentes temáticas lúdicas, ya sea des del ámbito sociológico, antropológico, cultural, deportivo, filosófico, poético... La propuesta se enmarca en el tratamiento filosófico, histórico y personal que Walter Benjamin hizo relacionado con esta temática. El objeto de estudio es, por lo tanto, esta aparición del juego y del juguete en el pensamiento del filósofo alemán, ya sea a partir de sus viajes, como de sus interpretaciones, que a menudo critican la sociedad de la época. La metodología utilizada se ha basado en el análisis de sus principales textos. Estas fuentes primarias vienen reforzadas por un conjunto de aportaciones que contextualizan el discurso de Benjamin. Los resultados permiten comprobar la importancia que Benjamin dio a estos elementos -juego y juguetey su evolución sufrida. Se proponen un conjunto de acciones que hagan volver el sentido original de la acción de jugar y se desprendan de la lacra del consumismo. El pensamiento del filósofo alemán puede convertirse, por lo tanto, en un punto de apoyo, de recuperación de la memoria histórica y en favor de una educación del juego, del juguete -y como no, del deporte-crítica y real.

Palabras clave: educación crítica; juego; juguetes; memoria histórica; sociedad; Walter Benjamin.

\footnotetext{
1 https://orcid.org/0000-0002-3582-9826.

2 https://orcid.org/0000-0002-9669-0485.
} 


\begin{abstract}
Games and toys must be treated from different points of view if we want to get a global idea of their importance. For all this, it's necessary to analyze different characters that have treated the different playful themes, whether from the sociological, anthropological, cultural, sports, philosophical, poetic field... The proposal is framed in the philosophical, historical and personal treatment that Walter Benjamin did related to this theme. The object of study is this appearance of the game and the toy in the thinking of the German philosopher, whether from his travels, as from his interpretations, which often criticize the society of the time. Methodology used has been based on the analysis of its main texts. These primary sources are reinforced by a set of contributions that contextualize Benjamin's speech. Results allow us to verify the importance that Benjamin gave to these elements -game and toy- and their evolution. A set of actions are proposed that bring back the original meaning of the action of playing and detach from the scourge of consumerism. The thought of the German philosopher can therefore become a foothold, of recovering historical memory and in favor of an education of the game, of the toy - and of course, of sport - critical and real.
\end{abstract}

Keywords: Critical education; game; historical memory; society; toys; Walter Benjamin.

SUMARIO: 1. Introducción. 2. Juegos, juguetes, niños y sociedad. 3. Juegos, juguetes y niños: hábitos, mimetismo y dominación. 4. A modo de conclusión (para un uso menos consumista del juego-juguete). 5. Referencias bibliográficas.

\title{
1. INTRODUCCIÓN
}

En la actualidad, el desequilibrio del poder en favor de individuos-clases, que cada vez disponen de más instrumentos -y más poderosos- se hace evidente. Estos grupos económico-políticos van dominando los diferentes ámbitos susceptibles de influencia hacia la población: medios de comunicación, escuela, redes sociales... Y bajo el engaño de un mundo libre y de autonomía del individuo, el individuo queda bien limitado-controlado por un conjunto de estímulos-procedimientos que lo guían-conducen, con precisión, a la sumisión de aceptar unos valores predeterminados-correctos (Foucault, 2008; Jordana, 2018; Torrebadella, 2019). Ejemplos de ello son: el vestir, determinado por las tendencias que van surgiendo; la forma de relacionarse con los otros individuos; los currículums escolares bien prefijados, elaborados por no se sabe quién y desconociendo y ocultando su finalidad real... Y el juego/deporte no es un elemento aislado. Por ejemplo, los deportes de masas son medios perfectos de consumo, de pérdida de tiempo intelectual, de potenciación de un modelo competitivo, de rivalidad, y de consumo constante -ya sea comprando camisetas de los equipos e ídolos, como escuchando y visualizando debates sin contenido, o consumiendo modos de hablar y de actuar de estos héroes del siglo XXI, que son a la vez, para el poder económico, simples objetos publicitarios-. De modo parecido pasa lo mismo con los juguetes. Como en cualquier moda, periódicamente aparecen nuevas tendencias que habrá que comprar y que hacen surgir en estos objetos una obsolescencia programada casi perfecta -cuando aparece un nuevo juguete de consumo, el anterior queda olvidado-. Lo mismo sucede con los 
videojuegos: aparecen nuevos juegos, nuevas versiones que únicamente buscan que el practicante desembolse su dinero y mediante su constante adicción. Asimismo, todo este fenómeno llega a su máximo exponencial con los macroeventos como los campeonatos de e-sports. $Y$ en relación con los juegos y juguetes, refuerza esta hipótesis el hecho que hayan desaparecido -vayan olvidándose- todo un conjunto de prácticas y artefactos tradicionales (Escriu \& Brasó, 2019), que ya no son pertinentes-óptimos para el consumo del siglo XXI, al contrario, lo perjudican: perjudican la economía (Andújar y Brasó, 2017; Brasó y Collell, 2016; Brasó y Torrebadella, 2014). Estas tendencias esconden unos determinados valores -que se pretenden inculcar-. No es fácil descubrir el sexismo, las jerarquías, el poder de clases, la sumisión... -moda, juguetes, prensa, escuela, amigos, etc.-. Y estos poderes, por lo tanto, y en la línea de las interpretaciones de la escuela de Frankfurt, son los mismos que escriben la historia.

Este ideal-filosofía lúdica es tratada por diversos personajes en diferentes tiempos. Centramos el estudio en los pensamientos de Walter Benjamin (Berlín, 1892-Portbou, 1940), muy crítico con esta historia oficial y que buscó en los deshechos otra mirada de la historia. Opinaba que una buena manera de tratar el pasado era analizando los juguetes. El objeto de estudio, por lo tanto, se basa en el tratamiento del juguete $-\mathrm{y}$ del juego- en la filosofía de Benjamin. La metodología se ha basado en el análisis de sus textos que permiten conformar una parte de su visión del mundo y de lo lúdico. Estas fuentes primarias se refuerzan con fuentes secundarias, que contextualizan el discurso. Posteriormente, se propone un seguido de acciones-propuestas para hacer un tratamiento del juego más sostenible, no convencional, más humanista (Garcia \& Brasó, 2019), y ofrecer un trabajo de recuperación de la memoria histórica.

\section{JUEGOS, JUGUETES, NIÑOS Y SOCIEDAD}

El interés por recordar el pasado es un hecho que Benjamin (2014b) analiza. En este sentido la búsqueda desordenada, no es un proceso menor que un trabajo puramente de inventario: «Sin duda vale muchísimo la pena ir siguiendo un plan al excavar. Pero igualmente es imprescindible dar la palada a tientas hacia el oscuro reino de la Tierra... se pierde lo mejor aquel que sólo hace el inventario fiel de los hallazgos y no puede indicar en el suelo actual los lugares en donde se guarda lo antiguo» (Benjamín, 2014b, p. 141).

La aparición sin más de los juegos y los juguetes son bien presentes en las obras, diarios y reflexiones de Benjamin (Capellà, 2014). En Diario a Moscú (2015a), el autor va puntualizando los juegos de ajedrez y de domino de diferentes personajes -y de él mismo-. En esta obra detalla a la vez el uso del trineo -juego por cierto bien común durante todas las épocas de la historia, y del que se asemeja al 
juego del carro infantil, presente ya en la infancia de la antigua Grecia (Hemelryk, 1992) - como elemento de desplazamiento entre los habitantes de la zona. Se fija ya en los diferentes tipos de trineos, desde los más sencillos hasta «los bobsleighs más confortables» (Benjamin, 2014b, p. 59). Y en Moscú impera la sencillez de estos medios de transporte -que son y serán a la vez juguetes- hecho que significa también que se piense "primero en el caballo... después en el pasajero» (Benjamín, 2014b, p. 41).

También, en Calle de dirección única $(1955,2014 a)^{3}$, y mediante aforismos rememorando la infancia, aparecen de nuevo los juguetes. Se fija en diferentes tipologías de juguetes y su entorno, y desde diferentes puntos de vista. Habla de los pliegos de figuras recortables, de las casetas de tiro al blanco, de muñecos de diferente tipología. Y relacionando el instrumento y elemento lúdico con la gestualidad y el simbolismo, se fija en Groos y Gröber, y detalla la propuesta de Haas, relacionada con posibles tipologías de juegos: de persecución ${ }^{4}$; los que la hembra defiende el nido ${ }^{5}$; de pelea por la presa, por un objeto, también objeto sexual ${ }^{6}$. Añade Benjamin (2015b, p. 30) que habría que interpretar, buscar y reflexionar sobre el dualismo de juguetes como: el «aro y palo, peonza y látigo, pelota y paleta, y el magnetismo originado entre ambas partes» y "la ley de la repetición como elemento permanente en todos estos juegos y juguetes».

Pero no puede entenderse esta obsesión de Walter Benjamin por el juguete sin comprender la importancia del objeto en su país, Alemania:

Si Alemania es el centro geográfico de Europa, también ha sido el centro espiritual en el terreno del juguete. Porque buena parte de las piezas más hermosas que aún hoy encontramos en los muesos y en los cuartos de los niños pueden considerarse como un obsequio que Alemania ha hecho a Europa (Benjamin, 2015b, p. 17).

Y se fija en la segunda mitad del siglo XIX como el momento clave en el que aparece la industrialización del juguete -que llegará más tarde en España (Capellà, 2016; Corredor-Matheos, 1981, 1999; Payà, 2014)- y su alienamiento de la familia:

En la segunda mitad del siglo XIX, cuando comienza la definitiva decadencia de estas baratijas, observamos cómo los juguetes se van agrandando, cómo van perdiendo su sencillez, su delicadeza. Fue entonces cuando los niños empezaron a tener su propio cuarto de juegos, su propio estante de libros, distintos de los de los padres. No cabe duda de que los tomos antiguos, con sus formatos pequeños exigían mucho más

${ }^{3}$ Terminado en 1926, pero publicado en 1928.

${ }^{4}$ Como el juego del gato y el ratón.

${ }^{5}$ Como el portero en el futbol o el tenista en el tenis.

${ }^{6}$ Como el futbol o el polo, por ejemplo. 
entrañablemente la presencia de la madre mientras los modernos... permiten prescindir de la presencia de la madre. Se inicia entonces la emancipación del juguete; cuanto más se impone la industrialización, tanto más se sustrae al control de la familia, volviéndose cada vez más extraño, tanto para los niños como para los padres (Benjamin, 2015b, p. 20).

Así, el juguete con la industrialización se desprende de la familia, y pierde parte de su esencia. Y también se pierde la creatividad para el juego:

Mientras dominó el rígido naturalismo, no existió la posibilidad de mostrar el verdadero rostro del niño que juega. Puede ser que hoy ya estemos en condiciones de superar el error fundamental de considerar la carga imaginativa de los juguetes como determinante del juego del niño; en realidad sucede más bien al revés. Si el niño quiere arrastrar algo, se convierte en caballo; si quiere esconderse se hace ladrón o gendarme. Conocemos algunos juguetes antiquísimos que prescinden de toda máscara imaginativa (es posible que, en su tiempo, hayan sido objetos de culto): la pelota, el arco, el molinete de plumas, el barrilete, son todos objetos genuinos, "tanto más genuinos cuanto menos le significan para el adulto". Porque cuanto más atractivos, en el sentido común de la palabra, son los juguetes, tanto menos "útiles" son para jugar; cuanto más ilimitada se manifiesta en ellos la imitación, tanto más se alejan del juego real, vivido. [...] La imitación -así podríamos formularlo- es propia del juego, no del juguete (Benjamin, 2015b, p. 22). ${ }^{7}$

Benjamin considera los juguetes elementos contextualizados de la sociedad. Así, si los niños se enmarcan en el pueblo, sus juegos y juguetes también tienen esta relación colectiva, que marcará una determinada historia:

Los niños no constituyen una comunidad aislada, sino que son parte del pueblo de la clase de la que proceden... sus juguetes no dan testimonio de una vida autónoma, sino que son un diálogo mudo basado en signos entre ellos y sus pueblos. Ese mundo infantil podría comprenderse, al igual que el arte popular, como una configuración colectiva, un universo de signos que expresa una situación histórica específica (Benjamin, 2015b, pp. $22-23)^{8}$.

Hay que entender el juego y el juguete con todas estas relaciones y es incomprensible su estudio aislado (Payà, 2013). Y del mismo modo que la lógica externa ${ }^{9}$ en el mundo del deporte es indispensable estudiarla; el juguete también hay que estudiarlo en esta globalidad -y relacionarlo con la clase social, el lugar de práctica, las tiendas de juguetes, el nivel de aceptación de la sociedad, las variantes constructivas y de juego del mismo juguete entre los diferentes pueblos, etc.-. De todo ello,

\footnotetext{
7 Publicado en mayo de 1928 en el Frankfurter Zeitung.

8 Publicado en mayo de 1928 en el Frankfurter Zeitung.

${ }^{9}$ Es decir, la afición, la prensa, los clubes, los seguidores...
} 
y con esta visión, Benjamin propone cuestiones relacionadas con finalidades -incluso falsas-que los adultos piensan que hay en el acto de jugar, cuando posiblemente el sentido lúdico esencial es independiente a este adulto:

El juego, por su parte, tiene sin duda algo de atávico: 'el juego es la partera de todo hábito'. Si el hábito nace de la reiteración, ¿cuál sería la razón de la misma: ¿acaso la imitación, la mímesis? ¿El niño estaría con el juego imitando al adulto y éste, mediante el juguete que fabrica, integrando al niño en el mundo de los adultos? ¿No será que el propio adulto se autoengaña con supuestas prácticas pedagógicas mientras el niño en su 'juguemos otra vez' pone en práctica un conocimiento más verdadero de la vida y de las cosas, de modo muy parecido a como procede el coleccionista, cuya pasión es siempre anárquica, destructiva...? (Benjamin, 2015b, p. 7).

Y seguramente, ligado a esta industrialización y posible olvido, aparece la necesidad, sensibilidad e interés por el coleccionismo de juguetes. Por todo ello hace una labor de buscar estos instrumentos en diferentes museos de juguetes, de artes o de oficios. Es, como diría el propio personaje, un modo de comprender la historia a partir de los deshechos.

\section{JUEGOS, JUGUETES Y NIÑOS: HÁBITOS, MIMETISMO Y DOMINACIÓN}

El juego de los niños lo lleva a tratar, por lo tanto, también los niños, su modo de vida, sus aficiones, o las relaciones con la familia. A modo de ejemplo, analizando la escuela en Moscú trata todo su interior, murales, cuadros, instrumentos y también sus métodos educativos, como el teatro pedagógico (Benjamin, 2014b). El pensador habla de la importancia del mimetismo y de la capacidad del ser humano de producir semejanzas. Y es que «la naturaleza causa semajanzas» (2010, p. 213). Esta facultad la relaciona el autor con el juego infantil, el cual se convierte en la escuela de la ontogenética. Recalca Benjamin que «el juego infantil está lleno de comportamientos miméticos, y su ámbito no se limita en absoluto a lo que una persona imita de otra. El niño no juega solamente a ser un maestro o un vendedor, sino también a ser un ferrocarril o un molino de viento» (2010, p. 214; 2008, p. 163). A partir de esta idea, reflexiona el pensador sobre el deterioro-pérdida -¿o transformación?- de la facultad mimética en la evolución filogenética del hombre. Y ello nos lleva a evidenciar que esta pérdida de la facultad mimética en los juegos, las danzas, el folklore... hace olvidar comportamientos que se iban repitiendo generación tras generación.

También se fija Benjamin (2015b, p. 31) en el modo que adquieren los hábitos los niños y comprueba que el juego ayuda a promover diferentes actitudes y modos de conducta: «comer, dormir, vestirse, lavarse, tienen que inculcarse al pequeño en 
forma de juego, al ritmo que marcan las canciones infantiles». Todo ello se relaciona también con la continua imitación que el niño hace a través del juego y del juguete. Si «la naturaleza produce semejanzas» (Benjamin, 2008, p. 163), el juego es su procedimiento. El juego permite este aprendizaje y explica la evolución filogenética y ontogénica. A la vez, para el pensador, la propia tarea autónoma y anárquica del niño tiene que tenerse en cuenta -por parte del adulto- a fin de evitar la -erróneaintervención del adulto a través de sus creaciones -materiales, juguetes...-:

Cavilar pedantemente sobre la fabricación de objetos (material didáctico, juguetes o libros) que sean adecuados para los niños es una estupidez. Desde la llustración, esto es una de las más enmohecidas especulaciones de los pedagogos. Su fascinación por la psicología les impide darse cuenta de que la Tierra está llena de los objetos más incomparables para la atención y el ejercicio infantiles (2014a, p.19).

\section{Y añade que:}

los niños siempre tienden de manera especial a visitar cualquier lugar donde se esté trabajando, donde se vea que las cosas poseen un uso. Los niños se sienten atraídos irresistiblemente por la basura que se produce en la construcción, en las tareas domésticas, en la jardinería, en las sastrerías o en las carpinterías [...] Los niños forman de este modo su propio mundo de cosas, un pequeño mundo en el mundo grande. Así, a las normas de este pequeño mundo de cosas ha de atenerse el que quiera crear para los niños, en vez de dejar que la actividad (con todos sus complementos e instrumentos) encuentre por sí misma el camino a ellos (2014, p. 19).

Se visualizan en estos textos las ideas del autor en relación con entender el mundo, y propone un modelo de educación en el que el adulto no intervenga en el juego, imponiendo normas y directrices. El juego y el juguete son en sí dos elementos que acaban siendo muy a menudo impuestos por el colectivo de adultos:

así como el mundo de la percepción del niño muestra por todas partes las huellas de la generación anterior y procura superarlas, lo mismo ocurre con sus juegos. Es imposible confinarlos a una esfera de fantasía, al idílico ámbito de una infancia o un arte puros. Incluso cuando el juguete es imitación de las herramientas del adulto es también un punto de conflicto no tanto del niño con el adulto como de éste con aquél. Pues, ¿quién da al niño los juguetes sino los adultos? Y si bien el niño tendrá algún margen de libertad para rechazar las cosas, no pocos de los juguetes más antiguos (pelotas, aros, molinetes de plumas, barriletes) le habrán sido impuestos, por decirlo así, como enseres de culto que sólo más tarde se transformaron en juguetes, gracias en parte a la imaginación ejercida por el niño (Benjamin, 2015b, pp. 26-27) ${ }^{10}$

\footnotetext{
10 Publicado en junio de 1928 en Die literarische Welt.
} 
En esta línea Benjamin critica la idea errónea, en la que la necesidad de los niños determina el carácter de los juguetes. Y es que, al menos hasta el siglo XIX, el adulto era el ideal "en cuya imagen el educador trataba de formar a los niños» (Benjamin, 2015b, pp. 28-29). Y seguramente por ello: «la muñeca puede ser niña o adulta y, como ser subordinado, seguramente más a menudo niña». De este modo "lo que se llama arte popular no es otra cosa que bienes culturales de una clase dominante que han sido relegados y renacen al ser recogidos por un grupo social más amplio». Como consecuencia, y en una idea parecida a Grober, la cultura económica es un condicionante de los juguetes $-\mathrm{y}$ sus juegos-. $Y$ analizando las diferencias entre juguetes y juegos, el autor detalla que, si bien los juguetes siempre han sido pensados para los niños, no sucede así con los juegos, acción que se ha considerado desde una perspectiva del adulto, como una imitación de este mundo al que los más jóvenes tienen que conquistar, en una idea similar, por ejemplo, a Elschenbroich (1979).

Benjamin busca, como muchos otros pensadores, la relación del juego con la sociedad, la clase dominante, y los prejuicios de la población, bien controlados y dirigidos (Brasó y Escriu, 2019). Si el catolicismo permite proporcionar una leyenda «que legaliza todos los excesos» (Benjamin, 2014b, p. 7), lo mismo sucede con multitud de prejuicios e ideas ocultas impuestas. A modo de ejemplo, y refiriéndose a Italia, habla de los juegos del azar y la finalidad oculta que se busca en el proletariado:

La lotería... es el tipo exacto de la vida económica napolitana. Por eso, todos los sábados a las cuatro la gente va a agolparse ante la casa donde se extraen los números. Nápoles es una de las pocas ciudades con sorteo propio. Con lotería y monte de piedad, el Estado atenaza al proletariado: eso que le da con una mano se lo va quitando con la otra. La embriaguez reflexiva y liberal de los juegos del azar, en que participa toda la familia, es sustitutiva de la alcohólica. (Benjamin, 2014b, p. 15).

Todo ello tiene consecuencias negativas, y a la vez si se piensa en la gente que busca «su interés egoísta y privado cuando actúa, pero al tiempo su comportamiento está determinado más que nunca por los fuertes instintos de la masa» (Benjamin, 2014a, p. 22). Añade, en una idea similar a Ortega y Gasset que: "Es bien sabido que las exigencias de la ética siempre pasan a segundo plano en la lucha de intereses propia de la vida cotidiana» (Benjamín, 2014b). Las críticas a la pedagogía burguesa son claras -como sucede en la actualidad (Brasó, 2018; Brasó y Torrebadella, 2017, 2018)-. Benjamin opina que el «interés por el método es una actitud típicamente burguesa» (2015a, p. 58). La clase proletaria necesita "un ámbito objetivo dentro del cual educar» (p. 59). Asimismo, critica todo un conjunto de palabras-conceptos que la burguesía utiliza para disimular la lucha de clases en su pedagogía. Son palabras como 
prácticas imparciales, comprensivas, empáticas, o la idea misma del «amor al niño» (p. 65) ${ }^{11}$.

Es evidente que el ejemplo napolitano es transferible a diversas y numerosas situaciones del siglo XXI. Se ve claro en otro escrito sobre el juego:

Al igual que cualquier otra pasión, el juego se nos da a conocer cuando la chispa salta en el ámbito corporal de uno a otro centro, moviliza ora un órgano, ora otro, y en él reúne y pone límites a la entera existencia. Ahí está el plazo concedido a la derecha antes que caiga la bolita en la casilla. Pasa la mano al modo de un avión que fuera sobrevolando las columnas, difundiendo en sus surcos las distintas semillas de las fichas. Dicho plazo lo anuncia aquel instante -el único que queda reservado al oído- en que la bola entra en el torbellino y el jugador escucha cómo la fortuna va afinando su oscuro contrabajo. En el juego, que habla a todos los sentidos, incluido al atávico de la clarividencia, también le llega luego su turno a los ojos... El juego tiene apasionados seguidores que lo aman por sí mismo, sin duda no por lo que les da. Si les quita todo, cargarán la culpa sobre sí y dirán 'he jugado mal'. Este amor ya contiene a la remuneración propia de su esfuerzo, de modo que las pérdidas también son entrañables porque les permiten demostrar su capacidad de sacrificio (Benjamin, 2014b, pp. 175-176).

Benjamin (2004, p. 492) trata este placer que viene del destino: «en el burdel y en la sala de juego se trata del mismo gozo pecaminoso: poner el destino en el placer». Y en relación con esta ansia por los juegos de azar, y su evolución, destaca la relación con el juego del dinero de inicios del siglo xx: La Bolsa. Remarca, analizando París -aunque extrapolable a otras ciudades-, que:

El juego de la Bolsa hace retroceder los juegos de azar procedentes de la sociedad feudal. Las fantasmagorías del espacio, a las que se entrega el flâneur, se corresponden con las fantasmagorías del tiempo, de las que depende el jugador. El juego transforma el tiempo en una droga. Lafargue explica el juego como un símil a pequeña escala de los misterios de la situación bursátil (Benjamin, 2004, p. 47).

Concluye que todo ello termina en el lenguaje que es el estadio supremo de este comportamiento mimético "y el más perfecto archivo de semejanzas inmateriales» (Benjamin, 2008, p. 167). Y en esta lengua y su entendimiento surge la no violencia. La lengua es así «la verdadera y propia esfera del entenderse» (2008, p. 187). Transfiriéndolo al juego y al juguete, esta cuestión se asemeja al conjunto de reglas, normas, y también conductas morales no escritas. Sería el lenguaje del juego, del juguete y cómo no, del deporte, lenguaje que está a menudo guiado, dirigido por los aparatos económicos, ideológicos... como si el niño acabase siendo

${ }^{11}$ Fragmento de finales de 1928 o inicios de 1928 en Gesammelte Schriften. 
un simple autómata. Esta afirmación nos lleva a tratar sobre filosofía y teología, en una relación que el pensador propuso:

existía un autómata... que era capaz de responder a cada movimiento de un jugador de ajedrez, con otro movimiento que le aseguraba el triunfo en la partida... Un sistema de espejos producía la ilusión de que esta mesa era en todos los sentidos transparente. En realidad, había adentro un enano jorobado, el cual era un maestro para el ajedrez y movía la mano del muñeco mediante cordeles. Un equivalente de tal mecanismo puede imaginarse en la filosofía. Debe vencer siempre, el muñeco llamado 'materialismo histórico'. Puede competir sin más con cualquiera cuando pone a su servicio a la teología, la cual hoy, como resulta notorio, es pequeña y desagradable y no debe dejarse ver por nadie (Benjamin, 2008, p. 63).

El autómata -ajedrecista- ha sido tratado por Benjamin, y en diversas ocasiones (Allan Poe, 1918; Löhr, 2006). Podríamos relacionar el «juguete y su juego» como una imagen «que oculta bajo la mesa a la teología en los salones de la filosofía» (Sigüenza, 2013, p. 98). Surge así un discurso crítico a partir de la imagen pasada y que conforma una imagen dialéctica. Se interpretan, contextualizando el texto con todas sus tesis, tres temas tratados y que Sigüenza (2013) explican: la renovación crítica del materialismo histórico; la crítica al historicismo positivista y su concepto de progreso, y la crítica al marxismo vulgar.

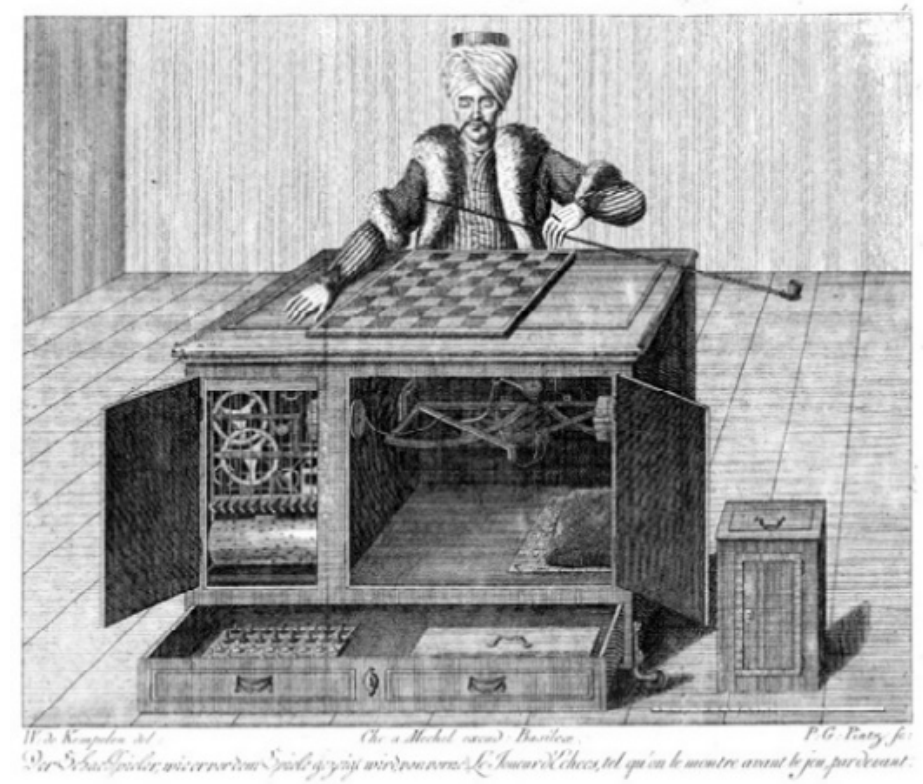

Figura 1. El Turco ${ }^{12}$, construido por Kempelen en 1769 (Gottlieb, 1783) en su obra.

12 Disponible en: <https://upload.wikimedia.org/wikipedia/commons/8/8b/Tuerkischer_ 
Estos pensamientos, concluyendo con esta imagen de la primera tesis, nos lleva a la actualidad y a cuestionarnos preguntas como: ¿En qué medida los juguetes de hoy en día, y los juegos potencian un modelo de niño-adulto acrítico? ¿Por qué los juguetes autoconstruibles por los niños no existen-han desaparecido? ¿Por qué los juguetes cada vez son más elaborados, más tecnológicos, y también más virtuales? ¿Por qué el elemento motriz general se ha casi eliminado del juego, predominando un modelo concreto mental? ¿Por qué los juegos tradicionales han desaparecido completamente del mundo del niño -juegos de cromos, la peonza, la rayuela, el aro? Estas serán las cuestiones que habrá que profundizar y promover para fomentar una nueva pedagogía lúdico-crítica anticapitalista.

\section{A MODO DE CONCLUSIÓN (PARA UN USO MENOS CONSUMISTA DEL JUEGO-JUGUETE)}

La visión del mundo, del juego y del juguete en Walter Benjamin no puede separarse de su perspectiva alemana. La sociedad de la época y la industrialización del s. XIX que llevan a deshumanizar el juguete y, en definitiva, a alienarlo son factores claves para entender su filosofía lúdica. En esta línea surgen y hay que tener en cuenta elementos como el tratamiento de la historia o el coleccionismo a través del juego y el juguete. $Y$ es que no se puede entender el juego sin comprender el contexto y momento social de una sociedad. Por todo ello, Benjamin ya plantea que hay que evitar caer en el olvido ni perder los orígenes, la tradición... y, en definitiva, la cultura propia. Y es que, como argumenta el filósofo, el juego es un elemento para aprender hábitos -también costumbres, tradiciones, modos de vida...- que se van transmitiendo de generación en generación. Pero destaca que también es una realidad la influencia de la economía y la búsqueda de las diferenciaciones sociales a través del juego. Aparece, por lo tanto, esta voluntad de sumisión que pretenden imponer las clases dominantes. Por lo tanto, ¿Cómo hay que tratar el juego en la sociedad actual? ¿Hay que mirar al pasado? ¿O solo al futuro?

Se hace necesaria así una (re)visión (crítica) del juego y el juguete. Se podría partir de la idea que propone el filósofo cuando detalla que: "La fuerza de la carretera es diferente si la recorremos a pie o la sobrevolamos en aeroplano. También la fuerza de un texto es diferente si lo leemos o bien si lo copiamos» (Benjamin, 2014a, p. 16). ¿Podríamos decir lo mismo del juego y el juguete? Es evidente que actualmente los juguetes son un simple instrumento -del mismo modo que lo es la educación escolar (Torrebadella, 2017)-. Se exponen en los medios de comunicación para que sean consumidos y casi siempre de modo rápido, en una sociedad líquida -o se dejan de utilizar por la propia obsolescencia programada del jugue-

schachspieler_windisch4.jpg> [consulta el 20 de diciembre de 2019]. 
te, o la mente del infante y la capacidad económica familiar permite olvidarse de este objeto lúdico, visualizar nuevos anuncios en los medios y consumir un nuevo producto-. Es por lo tanto evidente que ni el propio juguete se hace para que perdure mucho tiempo, ni los más pequeños están preparados -¿ientrenados?-para utilizarlos durante un período prolongado. Antiguamente, los juguetes tenían una mayor vida, y, además, se arreglaban porque eran caros. Por lo tanto, se interiorizaban, y esto incluso llegaba a su máxima exponencia cuando era el propio niño que construía el propio objeto lúdico.

Se desprende la necesidad de un nuevo modelo lúdico, que se aleje del fast play -también de la tecnologización que entierra el arte popular como ya apuntó cuando hablaba de la Rusia moderna (Benjamin, 2015a) - y se adentre en el slow play, con nuevos -o viejos y recuperados- juegos y juguetes, menos tecnológicos, menos elaborados, pero más funcionales, más diversos y, en definitiva: más libres y emancipatorios. ¿Pero cómo se puede conseguir este objetivo en una sociedad donde impera el consumo, la rapidez, la tecnología y la novedad -y que quiere olvidar el pasado y los orígenes-? Se proponen diferentes acciones para concienciar y promover un nuevo uso del juguete, alejado de este modelo lúdico-consumista:

- Elaboración de juguetes, como por ejemplo teatros, cometas o muñecas.

- Práctica con juguetes antiguos-olvidados como loa peonza, el trompiche, los cromos, o las canicas.

- Búsqueda de juegos de la gente mayor, por ejemplo, en familiares y conocidos.

- Creación de un museo real -pero también virtual- de juegos y juguetes antiguos ${ }^{13}$.

- Puesta en práctica y exposición a los más pequeños de nuevas posibilidades lúdicas con estos juguetes.

- Elaboración y divulgación de propuestas didácticas relacionadas con el ámbito de estudio del juguete y los juegos -y deportes- antiguos-olvidados.

- Potenciación del juego real, alejándose del entorno lúdico virtual.

Recordar el pasado es necesario para mantener la identidad cultural. El juguete, y el juego, son elementos que conforman las sociedades y a partir de ellos podemos entender un pueblo, un modo de ser, de manera más transversal y profunda que seguramente con libros de cultura e historia. Para una educación crítica hay que mantener esta tradición a un mundo, que consume y olvida -ni se percata de reciclar ideas, momentos, filosofías...-. Y cualquier propuesta que pretenda recuperar alguna situación o momento histórico será necesaria y válida para mantener viva la llama del humanismo.

${ }^{13}$ A modo de ejemplo partes de la propuesta del Museu del Joguet (Figueres, Catalunya), pueden ser transferidas en otros ámbitos locales. 


\section{REFERENCIAS BIBLIOGRÁFICAS}

Allan Poe, E. (1918). Nuevas historia extraordinarias. Madrid: Matev.

Andújar, I.y Brasó, J. (2017). La lógica interna en Los Juegos de niños (1560) de Peter Brueghel. RICYDE, Revista Internacional de Ciencias de la Actividad Física y el Deporte, 13(50), pp. 426-441. https://doi.org/10.5232/ ricyde2017.05008.

Benjamin, W. (1955). Dirección única. Madrid: Alfaguara.

Benjamin, W. (2004). Libro de los pasajes. Madrid: Akal.

Benjamin, W. (2008). Ensayos escogidos. México: Coyoacán.

Benjamin, W. (2010). Walter Benjamin. Obras. Libro II / vol. 1. Madrid: Abada.

Benjamin, W. (2014a). Calle de dirección única. Madrid: Abada.

Benjamin, W. (2014b). Imágenes que piensan. Madrid: Abada.

Benjamin, W. (2015a). Diario a Moscú. Madrid: Abada.

Benjamin, W. (2015b). Juguetes. Madrid: Casimiro.

Brasó, J. (2018). Pedagogía crítica: Recuperar el pasado para enfrentar el presente... y cambiar el futuro. Revista Cronopio, 80. http://www.revistacronopio. $\mathrm{com} / \mathrm{p}=22690$.

Brasó, J. y Collell, X. (2016). El joc popular de la xarranca. Estudi a través dels llibres i del folklore català. Possibles aplicacions en l'àmbit escolar. REIRE. Revista d'Innovació i Recerca en Educació, 9(2), pp. 82-105. https://doi.org/10.1344/ reire2016.9.2926.

Brasó, J. y Escriu, S. (2019). Possibilitats del joc i l'esport per reformar la societat. Perspectiva escolar, 405, pp. 6-11.

Brasó, J. y Torrebadella, X. (2014). El joc del 'rescat' a Catalunya. Un projecte educatiu a l'Escola del Mar de Pere Vergés. Temps d'Educació, 47, pp. 191-212. https://doi.org/10.1344/reire2015.8.2822. 
Brasó, J. y Torrebadella, X. (2017). ¿Por qué nos hacen jugar en la escuela? Reflexiones pedagógicas para entender (¿criticar?) la enseñanza actual. En XIV Congreso Internacional de Teoría de la Educación (pp. 541-549). CITE. Murcia: Universidad de Murcia.

Brasó, J. y Torrebadella, X. (2018). Reflexiones para (re)formular una educación física crítica. Revista Internacional de Medicina y Ciencias de la Actividad Física y el Deporte, 18(71), pp. 441-462. https://doi.org/10.15366/rimcafd2018.71.003.

Capellà, P. (2014). La història de la joguina: estat de la qüestió d'una reconstrucció disciplinària. Educació i Història: revista d'Història de l'Educació (24), pp. 219242.

Capellà, P. (2016) La industria de la muñeca en España a través de sus invenciones, 1883-1914. El Futuro del Pasado, 7, pp. 353-405. https://doi.org/10.14516/ fdp.2016.007.001.013.

Corredor-Matheos, J. (1981). La joguina a Cataluña. Barcelona: Edicions 62

Corredor-Matheos, J. (1999). El juguete en España. Madrid: Espasa Calpe.

El enigma de Walter Benjamin. (2013). Acta Poetica, 34(2), pp. 77-100. https://doi. org/10.1016/S0185-3082(13)72404-0.

Elschenbroich, D. (1979). El juego de los niños. Madrid: Elschenbroich.

Escriu, S. y Brasó, J. (2019) Possibilitats del joc i l'esport per reformar la societat. Perspectiva escolar, 405, pp. 6-11.

Foucault, M. (2008). Vigilar y castigar. Nacimiento de la prisión. Madrid: Siglo Veintiuno.

Garcia, J. y Brasó, J. (2019). Semblances entre l'agogé lacedemònia i l'educació neoliberal actual. Reflexions per una educació crítica. Temps d'Educació, 56, pp. 17-36.

Gottlieb, K. (1783). Briefe über den Schachspieler des Hrn. von Kempelen, nebst drei Kupferstichen die diese berühmte Maschine vorstellen. Pressburg: s.e.

Hemelryk, J. (1992). El joc. En D, Vanhove, L'Esport a la Grècia Antiga (pp. 18-33). Barcelona: La Caixa. 
Jordana, E. (2018). Michel Foucault: Biopolítica i governamentalitat. Barcelona: Gedisa.

Löhr, R. (2006). La máquina del ajedrez. Barcelona: Grijalbo.

Payà, A. (2013). Aprender deleitando. El juego infantil en la pedagogía española del siglo XX. Bordón, 65(1), pp. 37-46.

Payà, A. (2014). Juego, juguete y educación en la pedagogía española contemporánea. Revista de Educación, 24, pp. 107-126. https://doi.org/10.13042/ brp.2013.65102.

Torrebadella, X. (2017). La militarización de la educación física escolar. Análisis de dos imágenes publicadas en la prensa de Barcelona de principios del siglo XX. Historia Social y de la Educación, 6(1), pp. 78-108. http://dx.doi.org/10.17583/ hse.2017.2296.

Torrebadella, X. (2019, 9 de julio). Genealogía de la educación física y deporte escolar en España. Una crítica ideológica a través de Foucault (Ponència). Segona Escola d'Estiu (juliol, 2019). Pensament pedagògic avançat: anàlisis genealògiques. Barcelona: Universitat de Barcelona, Departament de Teoria i Història de l'Educació, Grup de Recerca en Pensament Pedagògic i Social GREPPS-. https://ddd.uab.cat/record/212533 [consulta el 10 de enero de 2020]. 
Página intencionadamente en blanco. 